\title{
Attributional and Consequential Life-cycle Assessment in Biofuels: a Review of Recent Literature in the Context of System Boundaries
}

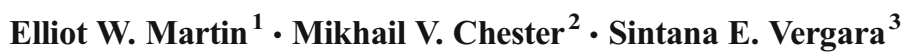

Published online: 25 August 2015

(C) Springer International Publishing AG 2015

\begin{abstract}
At the core of the debate over life-cycle assessment (LCA) modeling of the environmental impacts of biofuels is doubt that biofuels can mitigate climate change. Two types of LCA, attributional and consequential, have been applied to answer this question with competing results. These results turn on system boundary design, including feedstock considerations and assumptions of indirect land-use impacts. The broadening of the system boundary to include large scale land-use change of biofuel production has challenged the viability of biofuels to meet climate change goals. This paper reviews some of the latest literature in biofuels LCA exemplary of this debate and discusses the distinctions between attributional and consequential models in biofuels. We also present a generalized boundary map that can be used to convey LCA system boundaries clearly and succinctly within both attributional and consequential LCA.
\end{abstract}

Keywords Biofuels $\cdot$ System boundaries $\cdot$ LCA modeling · Life-cycle assessment

This article is part of the Topical Collection on Transportation

Elliot W. Martin

Elliot@berkeley.edu

1 Transportation Sustainability Research Center, University of California, Berkeley, CA, USA

2 Civil, Environmental, and Sustainable Engineering, Arizona State University, Tempe, AZ, USA

3 Energy \& Resources Group, University of California, Berkeley, CA, USA

\section{Introduction}

Assessing the environmental consequences of biofuels (using life-cycle assessment [LCA]) has been motivated by the search for viable alternatives to petroleum that yield lower greenhouse gas (GHG) emissions from transportation. LCA is among the leading frameworks for evaluating the system-wide impacts of biofuel production and informing related policy decisions. In short, LCA requires the consideration of environmental indicators and impacts occurring from cradle to grave. For a biofuel, this includes not only the $\mathrm{CO}_{2}$ released when the fuel is burned but also the emissions from, for example, the diesel tractor in the feedstock field. Since the early 2000s, biofuels have received considerable attention by LCA practitioners. LCA has been used to evaluate numerous biomass-to-energy pathways based on a variety of feedstocks. Much of the work leading up to the present decade has focused on feedstocks from existing agrarian crops such as corn [10, 15, 20, 24, 34, 40, 41], herbaceous plants $[30,31,36]$, and waste-based feedstocks such as municipal solid waste (MSW) [4, 17, 39]. More recently, LCA practitioners and biofuel researchers have assessed the use of less traditional feedstocks such as algae, seaweed, and waste residuals from agave, among others [24, 33, 37].

Expanding the scope of what is now called attributional LCA (ALCA) to include feedback effects of increasing production and use of a given fuel that are induced or caused by economic responses leads to consequential LCA (CLCA). One of the most salient effects of this expansion has been the discovery of indirect land use change (ILUC) discharges when wild land is cleared to increase agricultural production [32]. CLCA methods and system boundaries have also evolved to capture the broader implications of production and consumption decisions including carbon footprints, water use, and land use. With this growth in research has come debate about the applicability of LCA approaches to biofuels. 
Some have recently argued that biofuel CLCA may be misleading to policy makers by presenting results in the absence of disclosing large uncertainties [26•]. Others have suggested that biofuels LCA has accumulated inconsistencies across accounting methodologies and thus is subject to conflicting results [19]. The inconsistencies are especially pronounced with the use of different system boundaries, assumptions, and accounting practices for similar fuel pathways [10] and subsequently interfere with our understanding of biofuels. These inconsistencies raise questions about how LCA should inform production as well as policy maker decisions [21].

System boundaries vary by the type of LCA performed: attributional, which describes the environmentally relevant physical flows to and from subsystems within the overall system analyzed, and consequential, an evaluation of consequences of system actions [9]. In other words, ALCA evaluates a system that produces a product and assumes that the outside world is not influenced by decisions made within the system, so-called "product systems" [16•].

A product system would consist of all inputs and components necessary to produce a given output, such as the farm-to-refinery process required to produce ethanol. The additional inclusion of considerations such as the substitution of gasoline, indirect land-use change, or changes in emissions resulting from a fall in gasoline prices would broaden the ALCA to be a CLCA. When decision-makers outside the product system are modeled to react to the presence of the system outputs, the analysis is a CLCA. This distinction of concept began to emerge in the early 1990 s, but continues to be debated in LCA research today $[7,26 \bullet, 41,45]$. The debate has sought to distinguish ALCA from CLCA in their accuracy, uncertainty, and how they inform policy decisions. These distinctions have been explored through analyses of dedicated fuel feedstocks as well as MSW.

Feedstock crops are grown with the intention of being converted to a fuel, whereas waste feedstock is produced regardless of its future fate. LCA frameworks for crop-based biofuels are more mature than for waste-based fuels, but studies in each field utilize a variety of assumptions and system boundaries that make their comparison challenging. Analysis of waste feedstocks require their own set of rules for system boundary construction that can be applied to the comparative analysis of dedicated feedstock alternatives. This paper provides an overview of the previous and recent work in biofuels LCA, with comparative examples of ALCA and CLCA methodologies. Building on this review, we present generalized examples of system boundary diagrams that aim to convey simple ACLA and CLCA systems and discuss how such diagrams can efficiently and separately define the attributional and consequential components of each analysis.

\section{Recent ALCA and CLCA Biofuels Research}

Recent research in biofuels LCA has advanced understanding of the environmental consequences of new pathways and feedstocks for biofuel production. The field of biofuel LCA research has delved deeper into the indirect effects of biofuels and their overall influence on policy conclusions. Searchinger et al. [32] showed that biofuel production indirectly affects land use, and since then, several other studies [15], have modeled worldwide changes in land-use that would result in a shift from crop production to biofuels. These studies found that emissions from land-use change induced through world food markets may overwhelm the other benefits of displacing gasoline with ethanol derived from switchgrass or corn. The studies subsequently dampened the momentum behind climate-mitigating justifications for biofuels.

Tonini et al. [35•], a recent CLCA conducted in biofuels production analyzed 12 bioenergy scenarios with indirect land-use implications. They evaluated the perennial crops ryegrass, willow, and miscanthus as biofuel feedstocks, which have a number of advantages over traditional feedstocks including lower fertilizer requirements, higher yields, and increased soil carbon deposits. They found that when including energy production, substitution, and indirect land-use change that only one of their four conversion technologies were net negative in terms of GHG emissions over a 20 year horizon. Through a sensitivity analysis, they identified indirect landuse change as the primary source of uncertainty governing their results. Vázquez-Rowe et al. [38] also directly addressed the land-use impacts of biofuel policy by evaluating ten different CLCA scenarios surrounding land-use change as related to biogas production from corn in Luxembourg. Noting that uncertainties in CLCA can exceed those of ALCA, they use a partial equilibrium model to evaluate consequential land-use within Luxembourg and reported findings in line with the previous research. In the case of Luxembourg, they found impacts to be less negative since the shift of land-use within the country did not involve forest-clearing, as most of it has already been cleared.

The variance in conclusions as a result of the uncertainty of impacts is a common problem in CLCA of biofuels. While ALCA analyses tend to parse details and uncertainties about the "system process," CLCA in biofuels includes uncertainties that can be an order of magnitude bigger. In such cases, the potential and assumed consequences of indirect land-use change or some other process external to the product system can become large under modest assumptions of deterministic impact. Even with a sensitivity analysis, as executed by Tonini et al. [35•], for example, uncertainties can remain considerable and challenge biofuel CLCA in drawing policy conclusions.

Kumar and Murthy [18], performed an ACLA of tall fescue grass to ethanol production and found a range of 57 to $113 \%$ 
reduction in fossil energy use depending on which of four pretreatment technologies was applied in the absence of indirect consequential considerations. Kumar and Murthy [18] was notable because they applied a predefined process of system boundaries selection using the relative mass, energy, and economic (RMEE) value method as presented in Raynolds et al. [28]. Raynolds et al. [27] addressed the impending issue of inconsistent system boundary selection, as back then it was becoming an increasingly evident problem. The method is rigorous and numerical, which provides some needed structure to the selection process. It requires the researcher to define a functional unit for the LCA and to calculate the total mass, energy, and economic value of the unit, and further to define a cutoff ratio, which is some fraction (say $20 \%$ ) of the functional unit along these dimensions. Systems to be compared should share the same functional unit, e.g., a fixed mass of biofuel produced from a process. The masses, energy, and economic values of the inputs to each process upstream of the functional unit are compared to the analogous measures of the functional unit. If the ratio of inputs is larger than the cutoff, the process with those inputs is included, if not, it is excluded. The process is repeated until no additional systems are included. The method shown in Raynolds et al. [28] works well for an ALCA system boundary definition, but not as well for CLCA boundaries that include indirect land-use changes. These outside systems are not inputs to the core system, but are affected by it.

Rehl et al. [29] conducted a comparative ALCA and CLCA analysis of a biogas system. The CLCA approached involved modeling the substitution of co-products for an agrarian operation. In their analysis, they found benefits to both approaches under different circumstances and concluded that ALCA should be used when (1) the goal is to understand the contribution of individual components to system performance, or (2) the goal is to determine the optimal feedstock or production processes to produce the functional output with the highest efficiency. They noted that CLCA is primarily needed for policy making, when benefits of a process need to be proven under certain substitution scenarios. Both approaches need to be regularly subjected to rigorous sensitivity and uncertainty analysis.

Plevin et al. [26•] critique ACLA studies as characterizing impacts of a system as a deterministic change in some metric, usually GHGs, from a baseline business-asusual case, ignoring market effects. Further, they describe ALCA results as assuming away all indirect and scale effects on emissions resulting from a modeled system. They contend that ALCA results are misleading to policy makers, because they lend the appearance of precision in the face of broad uncertainty, while CLCA provides flexibility to evaluate scenarios outside of the core system of interest. Dale and Kim [6•] counter that the economic models which drive impact assessments such as indirect land use change are subject to great uncertainty and imprecision as well. In another response piece, Hertwich [15•] disputes the claim that ALCA is misleading, stating that LCA has traditionally been about product systems, which "comprises the activities required to deliver, utilize, and dispose of a product." He contends that the analytical models to conduct broad scale CLCA already exist as integrated assessment models, and that the LCA community should consider reinforcing these models as opposed to reinventing the wheel.

Dale and Kim [6•] also point out that though a great number of papers address indirect land use change from biofuels, far fewer studies address similar effects of petroleum resources. One that does is Yeh et al. [44], a comparative study of biofuel and petroleum derived land-use change. They found a comparable level of disturbances between the land use impacts of biofuels and petroleum in aggregate, but otherwise found that biofuels were inferior on a per energy basis relative to those land use impacts. Burnham et al. [3] conducted an ALCA of GHG emissions of shale gas as compared other petroleum sources as part of Argonne's GREET model development. However, studies otherwise evaluating the indirect impacts of petroleum are fewer relative to mass of literature that has explored the issue for biofuels during the current decade. Further work in this area is needed, particularly in consideration of the subterranean effects of enhanced oil recovery that has recently become widespread in North America.

\section{Waste LCA in Biofuels Research}

Use of waste feedstocks for biofuels has been less intensively studied. Because waste is not a cultivated crop for conversion to fuel, it requires different treatment within the context of LCA frameworks. Most waste LCA analyses focus on making the best waste management decision, not on choosing the best biofuel feedstock. Assessment of the environmental impacts of waste management systems has improved from the early modeling that considered individual components of the system separately to LCAs with more comprehensive scopes [5, 23, 25]. However, differences in system boundaries and allocation methods (especially for "avoided burdens") among models have led to considerable variation in results, even when the same system is being analyzed [4, 14, 17, 43].

Many waste LCA studies use a system boundary that includes the management system, but not the product manufacture and use systems, tracking waste from the moment of disposal until its conversion to an emission or a reusable product [22]. However, studies within the field of waste LCA use a variety of system boundaries that include 
different combinations of the energy and forestry sectors, land use changes, and displacement of virgin materials, and these differences in boundary can greatly impact results [39].

The accounting of environmental "gains" from waste management thus varies across studies.

Waste management facilities are generally sources of GHG emissions, which can be mitigated. But those reductions-from the displacement of fossil-based electricity or reduced virgin material based-manufacture - are usually credited outside the waste management system [13]. The variation in system boundaries is partially due to different GHG reporting methodologies. Gentil et al. [12] show that who is doing the accounting-whether a national organization, an LCA modeling group, a carbon trading mechanism or other organization-drives the system boundary used. Though LCA is supposed to be comprehensive and account for burden and benefit shifting, shifting still occurs due to the variation in system boundaries applied to analyses [11]. It is the benefit (not the burden) that most commonly shifts [12]. These differences in system boundaries, and the resulting inclusion and exclusion of environmental benefits and burdens, confound the comparison of different waste LCA studies.

Two key assumptions are near-universal in wastesourced fuel LCA, where the decision "on the table" is whether to use a quantity of waste for fuel or to do something else with it, such as placing it in a particular landfill. One assumption is that the release of biogenic $\mathrm{CO}_{2}$ is climate neutral $[2,13,27]$ and the other assumption is that waste carries with it no upstream environmental burdens from its production (the "zero burden assumption") [8]. Accepting the former assumption requires a relatively long time horizon, so that any carbon released from biogenic waste can be said to have been recently sequestered atmospheric carbon. The latter assumption holds that the emissions associated with the creation of a product would be the same no matter how it is managed as a waste product. This then implies that a waste-to-fuel LCA need not consider the upstream emissions associated with the production of that product (unlike corn ethanol). These upstream emissions are of course real and "counted" somewhere else, but they independent of the decision to convert waste to biofuel. The basis of the zero burden assumption is sound when comparing the environmental impacts of alternative fates for a quantity of waste. In this case, what happened to the material before it became waste does not matter with respect to decision-making (except in the special case where it can be shown that anticipating waste management somehow influences production decisions). The origin of the carbon in that waste is also inconsequential from the waste future decisionmaking perspective.

\section{Graphical Displays of System Boundaries in Biofuel LCA}

One of the challenges that have consistently hindered crosscomparisons of biofuel LCA studies is the clear, efficient, and consistent communication of system boundaries. Conveying system boundaries of analyses simply and clearly in graphical form is challenging but useful, as it provides the reader with a picture of system components, and the material flows among them. It also facilitates the comparison of systems efficiently, to better understand which components are included and excluded across conflicting studies. Results informing the performance of competing systems can turn on system boundary selection, thus identifying distinctions across studies is critical for synthesizing collective knowledge from the research community. We show general examples of two such diagrams for hypothetical ALCA and CLCA waste-to-biofuel systems. Figure 1 shows material flows for an ALCA of a product system that takes biogenic waste to be landfilled and instead converts it to a biofuel.

Figure 1 is a typical process flow diagram, but also illustrates the movement of carbon across three boundaries which divide (1) the atmosphere, (2) the product system, and (3) the Earth, where carbon is stored indefinitely. The arrows show all carbon flows accounted for in the analysis, complete from the feedstock carbon uptake to fuel combustion, and in the case of a real analysis, would convey values in units of mass (or energy). Flows that are prevented within the system are shown as dotted lines, and in the case of an ALCA, the substitution that causes avoided emissions must be deterministic. Although this is a substitution, in the case of waste LCA, the analysis is attributional because it is deterministic to the system; that is, waste diverted from the landfill to biofuel production has to result in avoided emissions and is not a market decision [2].

The system modeled within an ALCA is sometimes called a "foreground system", a system in which all components are critical to production of the output and generally under control of a single decision maker [42]. In practice, there are many decision makers in a system, but in the case of ALCA, the entire process could be controlled by a single firm with the enough resources to acquire or produce the feedstock and usher it through the modeled process. An ALCA becomes a CLCA when decision-makers receiving market signals in other, background systems are modeled within the overall LCA. They comprise impacts that are not deterministic as a result of the output of the foreground system.

Consumption substitution is one of the most common background systems included in LCA. Many studies assume that the production of a biofuel implies complete substitution of an energy equivalent amount of gasoline or diesel. In the US ethanol market, this is a reasonable assumption, since ethanol is blended with gasoline up to $10 \%$ and consumers rarely have a choice to consume unblended gasoline. Despite circumstances in favor of assuming complete substitution, 


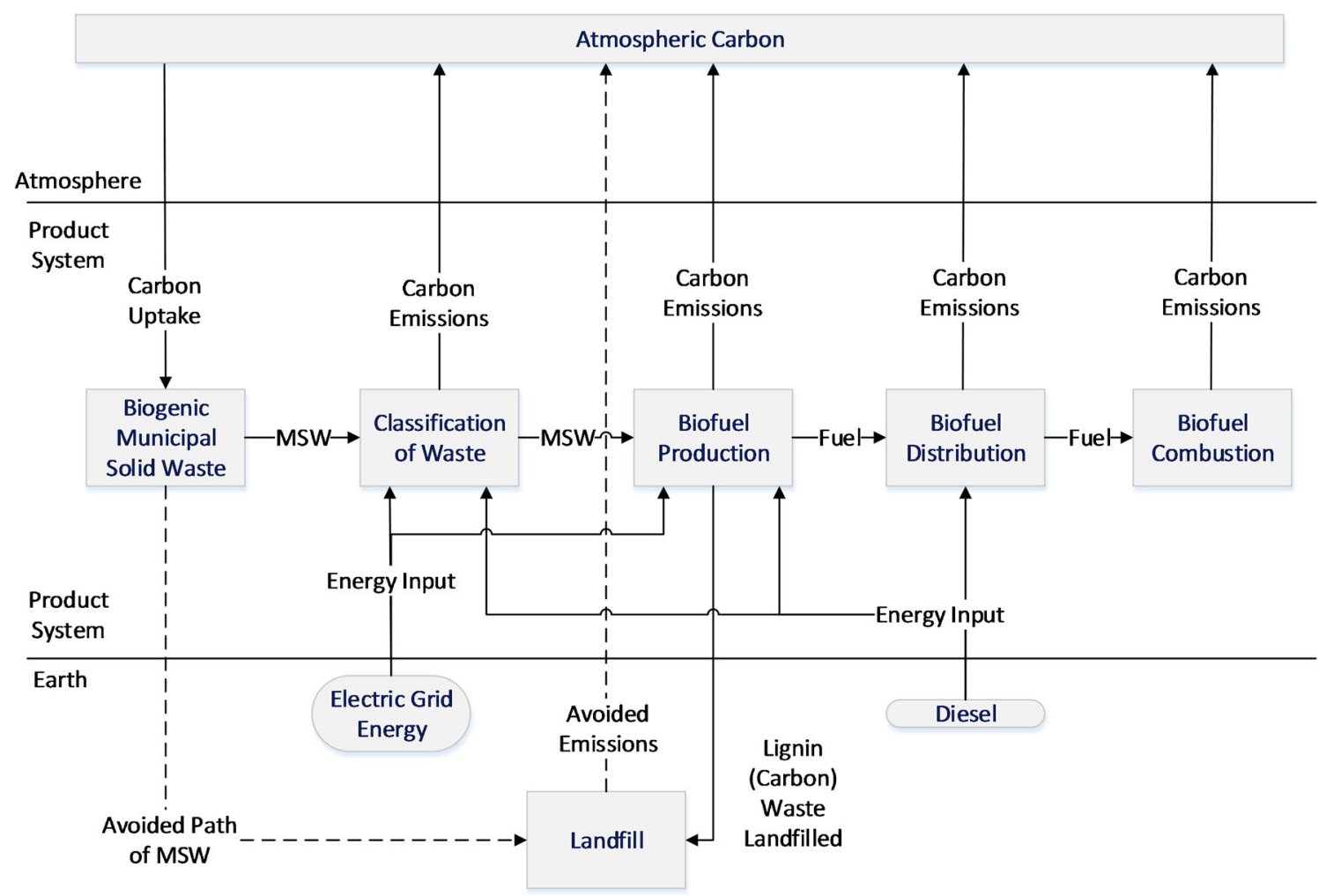

Fig. 1 Generalized system boundary diagram of an ALCA model of municipal waste-to-ethanol production system

researchers should acknowledge that the substitution is a market decision that is outside the powers of the producer operating the foreground system. Whenever such a substitution of consumption is considered, where decision-makers executing the substitution are not the same as those in the foreground system, the ALCA becomes a CLCA. With CLCA, there is an uncertainty that the modeled effects in the background system(s) will take place to the full extent. For example, the complete $1: 1$ substitution of the energy-equivalent amount of a fossil fuel for a biofuel may not occur. The actual substitution may only be partial (e.g., 1.05:1), where some of the fuel results in no substitution of consumption. One way this could occur is through a rebound effect, where a greater abundance of a biofuel leads to more driving than would otherwise occur.

Figure 2 shows an example of how a system boundary diagram could convey the divisions of foreground and background systems under the same generalized structure as Fig. 1.

Figure 2 contains the entire ALCA portion of Fig. 1, but also includes two background systems. One represents the substitution of consumption due to the product system and the other represents the substitution of production to the product system. A description of the decision made in the foreground system to produce the biofuel and the choices made by different decision-makers within the background systems are shown at the bottom of the figure. Generally, the output from a foreground system should in some way serve as an input to a background system for it to be included within a CLCA.

Different impacts within background systems will have different degrees of uncertainty for manifesting themselves. Consumption substitution is among the more certain impacts. Once a fuel is produced, it will likely be consumed at some price (even if below cost) and in place of some amount of another fuel. But changes in production decisions are a function of a market's producer prices, and the impact of these prices on producer decisions can be far less certain. Production scale from the foreground system and other exogenous market dynamics serve as critical inputs to production decisions elsewhere. For example, production of a biofuel at a small scale may not move producer prices or may not cause substantive land-use change in distant countries. Changes in production occur as a result of a broad set of market inputs, of which the scaled output of the foreground system may only be one. Uncertainties in the measurement of indirect land-use impacts and shifting production decisions are not discussed as often or as completely as they should be. Some models will convey the indirect effects from background systems as a guaranteed outcome based on the output of the foreground system. This yields one critique of biofuels LCA literature: that the divisions between foreground and background systems are not often delineated clearly and the uncertainty associated with impacts within background systems is not always fully quantified or disclosed. 


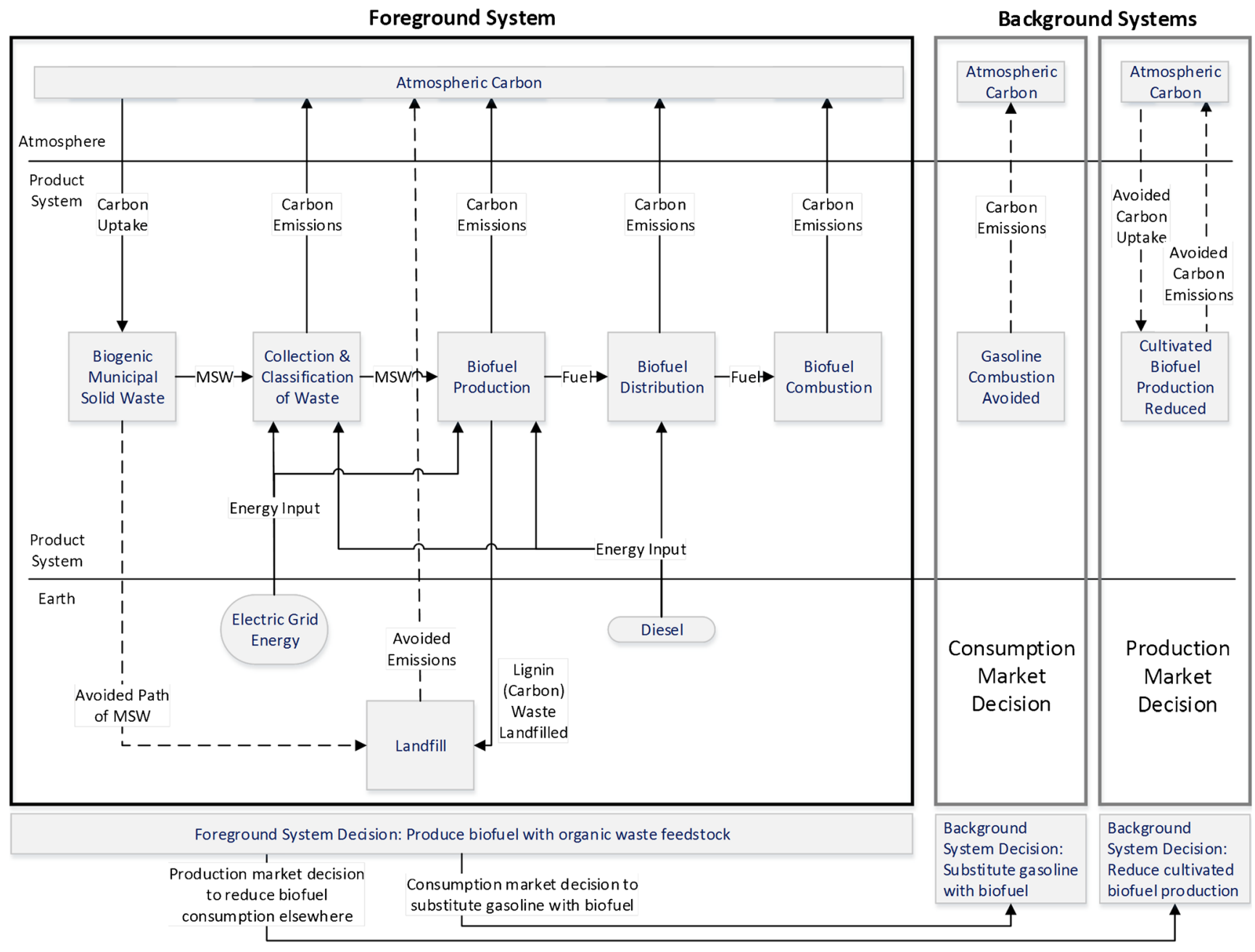

Fig. 2 Generalized system boundary diagram of a CLCA model of a municipal waste-to-ethanol production system

\section{Conclusion}

Biofuels LCA research has evolved over the last 20 years, exploring the impacts of unique feedstocks and production systems designed to produce a fossil fuel substitute that could mitigate climate change. The results of these efforts have been mixed, competing, and in some cases, contradictory based on different assumptions and system boundaries. For a while, it appeared that analyses akin to CLCA of biofuels with gasoline substitution showed modest benefits from fuels such as ethanol. But research quantifying the potentially large impacts of indirect land use change [32] changed this consensus rather rapidly and drastically. Subsequently, the inclusion of indirect impacts of land use change that could result from broader production-allocation decisions on a global scale changed the balance of impacts unfavorably for biofuels. Widespread production of biofuels, specifically ethanol, was reported to cause massive changes in global agricultural production with environmental impacts that would outweigh the modest benefits delivered from biofuels. The application of CLCA to these problems has vastly increased our understanding of the scope of lifecycle impacts as they relate to biofuels, and the exploration of indirect land-use impacts is an important example. But Dale and Kim [6•] point out that the direct and indirect land-use impacts of petroleum consumption have received far less attention. Outside of the comparative study by Yeh et al. [44•], and a few others, these indirect impacts of petroleum use have received limited attention relative to biofuels. Since that study, however, there has been rapid growth of hydraulic fracturing activity in the USA over a very short period of time that may have long-term impacts on landuse and the viability of subterranean assets, most notably water supplies. It is clear that advanced integrated CLCA models would be among the right tools to tackle these questions, and also clear that more work in this area is needed. Continued research in CLCA should also aim to better assess the uncertainties associated with predicted impacts derived from background systems. Transparency in conveying these uncertainties and system boundaries is important for clarity of research and for comparability across studies. Life cycle 
assessment in biofuels has undergone a considerable evolution since its early applications. As models become more advanced, and their scope become more global, applications of ALCA and CLCA should continue to enhance our understanding of impacts so as to inform the right policy decisions with respect to climate and biofuel alternatives.

Acknowledgments The authors would like to thank Michael O'Hare, a Professor of Public Policy at the Goldman School of Public Policy within the University of California, Berkeley, for making significant contributions to the development and advancement of this manuscript.

\section{Compliance with Ethics Guidelines}

Conflict of Interest Elliot Martin, Mikhail Chester, and Sintana Vergara declare that they have no conflict of interest.

Human and Animal Rights and Informed Consent This article does not contain any studies with human or animal subjects performed by any of the authors.

\section{References}

Papers of particular interest, published recently, have been highlighted as:

- Of importance

1. Azapagic A, Clift R. Life cycle assessment as a tool for improving process performance: a case study on boron products. Int J Life Cycle Assess. 1999;4(3):133-42.

2. Barton JR, Issaias I, Stentiford EI. Carbon-making the right choice for waste management in developing countries. Waste Manag. 2008;28(4):690-8.

3. Burnham A, Jeongwoo H, Clark C, Wang M, Dunn J, PalouRivera, I. Life-cycle greenhouse gas emissions of shale gas, natural gas, coal, and petroleum. Environ Sci Technol. 2012;46:619-27.

4. Chester M, Martin E. Cellulosic ethanol from municipal solid waste: a case study of the economic, energy, and greenhouse gas impacts in California. Environ Sci Technol. 2009;43(14):5183-9. doi:10.1021/es802788z.

5. Christensen TH, Gentil E, Boldrin A, Larsen A, Weidema B, Hauschild M. C balance, carbon dioxide emissions and global warming potentials. Waste Manag Res. 2009;27(8):707-15.

6. Dale B, Kim S. Can the predictions of consequential life cycle assessment be tested in the real world? Comment on "Using Attributional Life Cycle Assessment to Estimate Climate-Change Mitigation..." J Ind Ecol. 2014;18(3):466-7. Dale and Kim (2014) provide another important discussion on the Plevin et al (2013) paper. They note that CLCA is subject to considerable uncertainty and that the definition of a CLCA study is itself subject to some variance. They also poignantly note that many recent analyses have been overwhelmingly focused on indirect landuse of biofuels without considering in a balanced way the indirect land-use (and other) impacts of petroleum use.

7. Earles J, Halog A. Consequential life cycle assessment: a review. Int J Life Cycle Assess. 2011;16(5):445-53. doi:10.1007/s11367-0110275-9.
8. Ekvall T, Assefa G, Bjorklund A, Eriksson O, Finnveden G. What life-cycle assessment does and does not do in assessments of waste management. Waste Manag. 2007;27(8):989-96.

9. Ekvall T, Weidema BP. System boundaries and input data in consequential life cycle inventory analysis. Int J Life Cycle Assess. 2004;9(3):161-71. doi:10.1007/BF02994190.

10. Farrell AE, Plevin RJ, Turner BT, Jones AD, O'Hare M, Kammen DM. Ethanol can contribute to energy and environmental goals. Science. 2006;311(5760):506-8.

11. Finnveden G, Hauschild M, Ekvall T, Guinee J, Heijungs R, Hellweg S, et al. Recent development in life cycle assessment. J Environ Manag. 2009;91:1-21.

12. Gentil EC, Aoustin E, Christensen TH. Greenhouse gas accounting and waste management. Waste Manag Res. 2009;27(8):696-706.

13. Gentil EC, Clavreul J, Christensen TH. Global warming factor of MSW management in Europe. Waste Manag Res. 2009;27(9):850 60.

14. Heijungs R, Guinée J. Allocation and 'what-if' scenarios in life cycle assessment of waste management systems. Waste Manag. 2007;27(8):997-1005.

15. Hertel T, Golub A, Jones A, O'Hare M, Plevin R, Kammen D. Effects of US maize ethanol on global land use and greenhouse gas emissions: estimating market-mediated responses. Bioscience. 2010;60:223-31.

16. Hertwich, E. Understanding the climate mitigation benefits of product systems: comment on "Using Attributional Life Cycle Assessment to Estimate Climate-Change Mitigation..." J Ind Ecol. 2014;18(3):464-5. Hertwich (2014) provides a good discussion countering the critique of Plevin et al. Hertwich discusses some of the core ideas driving LCA methodology as about a product system. He points out that ALCA still has important applications for certain analyses, and raises some good questions about when CLCA should be most applicable.

17. Kalogo Y, Habibi S, Maclean H, Joshi S. Environmental implications of municipal solid waste-derived ethanol. Environ Sci Technol. 2007;41(1):35-41.

18. Kumar D, Murthy G. Life cycle assessment of energy and GHG emissions during ethanol production from grass straws using various pretreatment processes. Int J Life Cycle Assess. 2012;17:388 401.

19. Liska AJ, Cassman KG. Towards standardization of life-cycle metrics for biofuels: greenhouse gas emissions mitigation and net energy yield. J Biobased Mater Bioenergy. 2008;2(3):187-203.

20. Liska A, Yang H, Bremer V, Klopfenstein T, Walters D, Erickson G, et al. Improvements in life cycle energy efficiency and greenhouse gas emissions of corn- ethanol. J Ind Ecol. 2009;13(1):58-74.

21. Marland G. Accounting for carbon dioxide emissions from bioenergy systems. J Ind Ecol. 2010;14(6):866-9.

22. McDougall F, White P, Franke M, Hindle P. Integrated solid waste management: a life cycle inventory. 2nd ed. Oxford: Blackwell Science; 2001.

23. Morrissey AJ, Browne J. Waste management models and their application to sustainable waste management. Waste Manag. 2004;24(3):297-308.

24. Murillo-Alvarado et al. Optimization of the supply chain associated to the production of bioethanol from residues of agave from the tequila process in Mexico. Ind Eng Chem Res. 2014;53:5524-38.

25. OECD. Estimation of greenhouse gas emissions and sinks: Final report from the OECD experts meeting, 18-21 February, 1991. Paris: OECD; 1991.

26. Plevin R, Delucchi M, Creutzig F. Using attributional life cycle assessment to estimate climate-change mitigation benefits misleads policy makers. J Ind Ecol. 2013;18(1):73-83. Plevin et al. (2013) opens an important critique of ALCA in contrast to CLCA. Some authors disagree with the critique. Overall however, the 
work is an important recent framing piece over the debate regarding which LCA approach to use for given purposes.

27. Rabl A, Benoist A, Dron D, Peuportier B, Spadaro J, Zoughaib A. How to account for $\mathrm{CO} 2$ emissions from biomass in an LCA. Int $\mathrm{J}$ Life Cycle Assess. 2007;12(5):281.

28. Raynolds M, Fraser R, Checkel D. The Relative Mass-EnergyEconomic (RMEE) method for system boundary selection: part 1: a means to systematically and quantitatively select LCA boundaries. Int J Life Cycle Assess. 2000;5(1):37-46.

29. Rehl T, Lansche J, Müller J. Life cycle assessment of energy generation from biogas - attributional vs. consequential approach. Renew Sust Energ Rev. 2012;16:3766-75.

30. Sanderson MA, Adler PR, Boateng AA, Casler MD, Sarath G. Switchgrass as a biofuels feedstock in the USA. Can J Plant Sci. 2006;86:1315-25.

31. Schmer MR, Vogel KP, Mitchell RB, Perrin RK. Net energy of cellulosic ethanol from switchgrass. Proc Natl Acad Sci. 2008;105(2):464-9.

32. Searchinger T, Heimlich R, Houghton RA, Dong F, Elobeid A, Fabiosa J, et al. Use of U.S. croplands for biofuels increases greenhouse gases through emissions from land use change. Science. 2008;319:1238.

33. Sills D, Paramita V, Franke M, Johnson M, Akabas T, Greene C, et al. Quantitative uncertainty analysis of life cycle assessment for algal biofuel production. Environ Sci Technol. 2013;47:687-94.

34. Spatari S, Zhang Y, Maclean H. Life cycle assessment of switchgrass- and corn stover-derived ethanol-fueled automobiles. Environ Sci Technol. 2005;39:9750-8.

35. Tonini D, Hamelin L, Wenzel H, Astrup T. Energy production from perennial energy crops: a consequential LCA of 12 bioenergy scenarios including land use changes. Envrion Sci Technol. 2012;46: 13521-30. Tonini et al. (2012) provides a good example of a recent CLCA in biofuels production across a range of scenarios and feedstocks. They address uncertainty through a sensitivity analysis and consider impacts over a multi-decadal time horizon.
36. Vadas PA, Barnett KH, Undersander DJ. Economics and energy of ethanol production from alfalfa, corn, and switchgrass in the upper Midwest, USA. Bioenergy Resour. 2008;1:44-55.

37. van der Wal H, Sperber B, Houweling-Tan B, Bakker R, Brandenburg W, Contreras A. Production of acetone, butanol, and ethanol from biomass of the green seaweed Ulva lactuca. Bioresour Technol. 2013;128(2013):431-7.

38. Vázquez-Rowe I, Marvuglia A, Rege S, Benetto E. Applying consequential LCA to support energy policy: land use change effects of bioenergy production. Sci Total Environ. 2014;472:78-89.

39. Vergara S, Damagaard A, Horvath A. Boundaries matter: greenhouse gas emission reductions from alternative waste treatment strategies for California's municipal solid waste. Resour Conserv Recycl. 2011;57:87-97.

40. Wang $\mathrm{M}, \mathrm{Wu} \mathrm{M}$, Huo H. Life-cycle energy and greenhouse gas emission impacts of different corn ethanol plant types. Environ Res Lett. 2007;2:1-13.

41. Weidema BP. Market aspects in product life cycle inventory methodology. J Clean Prod. 1993;1(3-4):161-6.

42. Weidema B. New developments in the methodology for LCA. Presentation to the 3rd International Conference on Ecobalance. November 25-27, 1998. http://ca-net.com/files/developh.pdf.

43. Winkler J, Bilitewski B. Comparative evaluation of life cycle assessment models for solid waste management. Waste Manag. 2007;27(8):1021-31.

44. Yeh S, Jordaan S, Brandt AR, Turetsky MR, Spatari S, Keith DW. Land use greenhouse gas emissions from conventional oil production and oil sands. Environ Sci Technol. 2010;44(22): 8766-72. Yeh et al. (2010) is one of the few studies that does look at the indirect impacts of petroleum production. It should serve as an important reference for further exploration in area of work.

45. Zamagni A, Guinée J, Heijungs R, Masoni P, Raggi A. Lights and shadows in consequential LCA. Int J Life Cycle Assess. 2012;17: 904-018. 